\title{
Technical note: Developing a heat stress model in dairy cows using an electric heat blanket
}

\author{
M. Al-Qaisi, E. A. Horst, S. K. Kvidera, E. J. Mayorga, L. L. Timms, and L. H. Baumgard* \\ Department of Animal Science, lowa State University, Ames 50011
}

\section{ABSTRACT}

Precisely studying the biological consequences of heat stress (HS) in agriculturally relevant animals typically requires expensive climate-controlled facilities, infrastructure inaccessible to most researchers. Thus, study objectives were to explore the efficacy of an electric heat blanket (EHB) as an alternative method for evaluating HS and to determine whether EHB-induced hyperthermia affects production parameters similar to natural HS. Lactating Holstein cows $(\mathrm{n}=8 ; 133 \pm 3 \mathrm{~d}$ in milk; $709 \pm 31 \mathrm{~kg} ; 2.6 \pm 0.3$ parity) were housed in individual box stalls and allowed to acclimate for $3 \mathrm{~d}$. After acclimation, the trial consisted of 2 experimental periods $(\mathrm{P})$. During P1 (3 d), cows were housed in thermoneutral conditions for collecting baseline data. During P2 (7 d), cows were fitted with an EHB. During the entire experiment cows were fed ad libitum, and dry matter intake (DMI) was recorded daily. Cows were milked twice daily (0600 and $1800 \mathrm{~h}$ ), and milk samples were collected on d 2 and 3 of P1 and d 3 and 7 of P2. Rectal temperature, respiration rate, heart rate, and skin temperature were obtained twice daily (0600 and 1800 h) during both P1 and P2. Overall, there was an increase in rectal temperature and respiration rate at $0600 \mathrm{~h}\left(1.0^{\circ} \mathrm{C}\right.$ and 25 breaths $/ \mathrm{min}$, respectively) and $1800 \mathrm{~h}\left(1.2^{\circ} \mathrm{C}\right.$ and 29 breaths/min, respectively) during P2. The EHB decreased DMI and milk yield (25 and $21 \%$, respectively) by the end of P2. During P2, milk protein tended to decrease $(4.4 \%)$ compared with $\mathrm{P} 1$. In contrast, milk urea nitrogen increased $(33 \%)$ during $\mathrm{P} 2$ relative to $\mathrm{P} 1$. No other differences were observed in milk composition. In summary, our results indicate that employing an EHB affects physiological and production parameters similarly to natural HS (i.e., increased rectal temperature and respiration rate, decreased DMI and milk yield); thus, the EHB is an effective and inexpensive research tool for evaluating the biological consequences of HS in lactating dairy cows.

Received May 29, 2018.

Accepted August 28, 2018.

*Corresponding author: baumgard@iastate.edu
Key words: dairy cow, heat stress, electric blanket

\section{Technical Note}

Heat stress (HS) is an annual environmental issue negatively affecting a variety of production parameters, including milk yield and composition, growth, and reproduction (Baumgard and Rhoads, 2013). Heat stress occurs when environmental conditions, coupled with internal thermogenesis, create a heat load that exceeds thermolytic capacity (Bernabucci et al., 2010). Dairy cows are more susceptible to HS than most farm animals due to their high metabolic heat production and low surface area:mass ratio (West, 2003; Liu et al., 2014). The economic burden of HS is more than $\$ 1.5$ billion in the United States dairy industry alone (Key and Sneeringer, 2014). Although HS is an animal welfare and economic issue in developed nations, it is a key constraint to food security in many emerging economies (Baumgard and Rhoads, 2013). The negative consequences of HS will intensify if climate change and weather variability continue as predicted (Nardone et al., 2010) and genetic selection continues to emphasize economically important phenotypes, as these traits are accompanied by increased basal heat production (Spiers et al., 2004; Baumgard and Rhoads, 2013; Das et al., 2016).

Heat stress has indirect (via reduced feed intake) and direct effects on the endocrine system, metabolism, and immunoactivation (Baumgard and Rhoads, 2012, 2013). Heat-induced decreased DMI explains only about $50 \%$ of the decreased milk yield (Rhoads et al., 2009; Wheelock et al., 2010; Baumgard et al., 2011), and characterizing the underlying etiology behind the remaining decrease in production would presumably provide the necessary foundation to develop mitigation strategies. Thus, there remains an urgent need to thoroughly characterize the mechanisms by which HS decreases dairy cow productivity. Traditionally, environmental chambers have been required to design and conduct wellcontrolled HS studies in lactating dairy cows, especially if the experimental objectives are to isolate the direct effects of HS. However, due to construction and opera- 


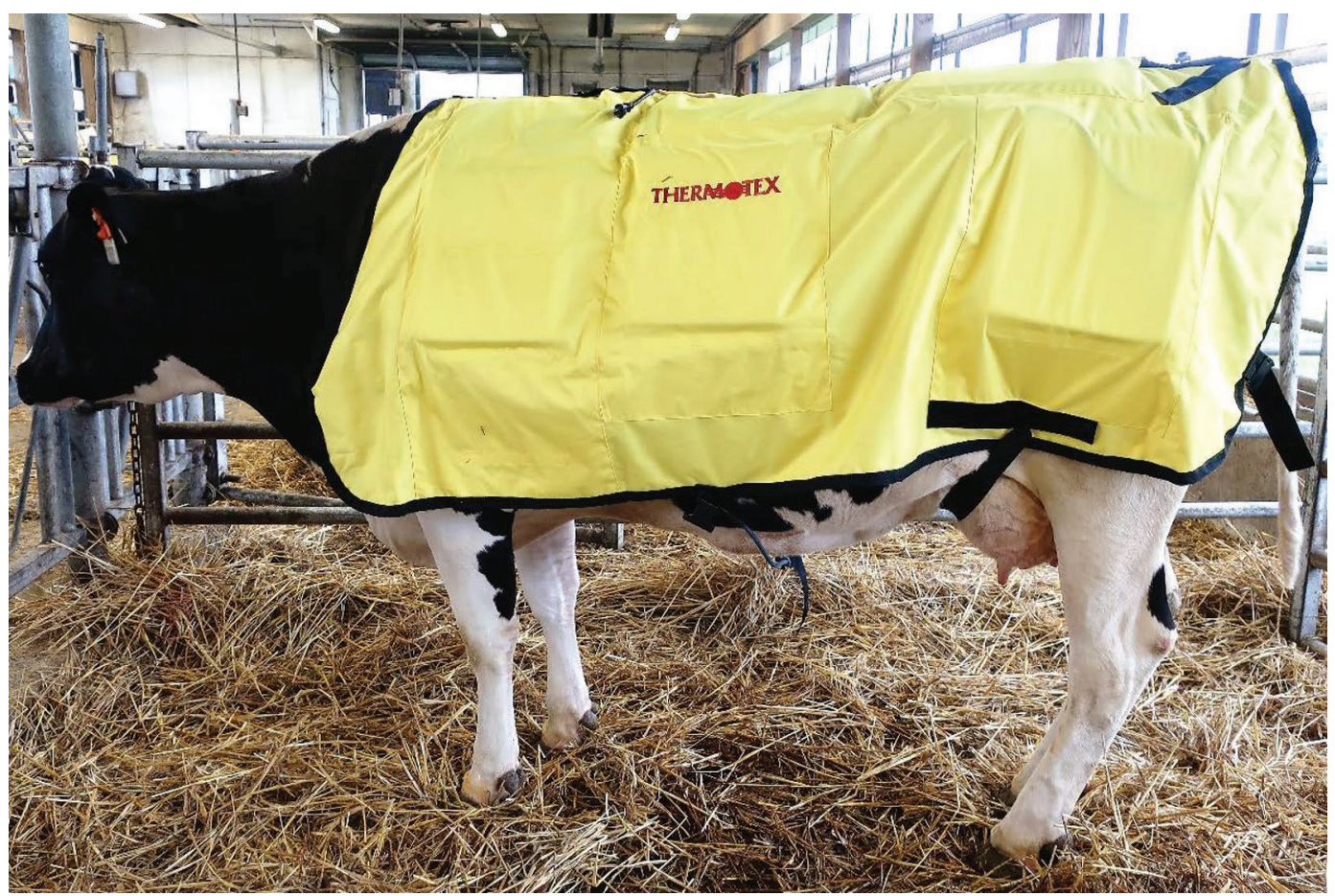

Figure 1. Holstein cow fitted with the electric heat blanket.

tion costs, many institutions lack the necessary facilities or resources. Hence, our objectives were to explore the efficacy of using an electric heat blanket (EHB) as an alternative and cost-effective method to study HS and to determine whether EHB-induced hyperthermia affects physiological and production parameters similar to natural HS. If effective, this alternative model would broaden accessibility to the environmental physiology discipline and likely hasten advances in the field of thermal biology.

Lactating Holstein cows $(\mathrm{n}=8 ; 133 \pm 3$ DIM; 709 $\pm 31 \mathrm{~kg}$ of BW; parity $2.6 \pm 0.3$ ) were housed in sandand straw-bedded individual box stalls $(4.57 \times 4.57 \mathrm{~m})$ within a naturally ventilated barn at the Iowa State University Dairy Farm (Ames) and were allowed to acclimate for $3 \mathrm{~d}$. The trial included 2 experimental periods $(\mathbf{P})$. During P1 (3 d), cows were fed ad libitum and housed in thermoneutral conditions for collecting baseline body temperature indices and production parameters (hence, each animal served as its own control). During P2 $(7 \mathrm{~d})$, cows were fitted with an EHB $(1.87 \times$ $1.59 \mathrm{~m} ; 100 \%$ nylon with polyurethane coating; weight $=7.7 \mathrm{~kg})$ consisting of 12 infrared heating pads as a heat source (Figure 1; Thermotex Therapy Systems Ltd., Calgary, AB, Canada); the EHB remained on the cows for the entirety of P2. The blanket was powered by a $110-\mathrm{V}$ electrical cord that connected to the EHB at the withers. The power cord was positioned on the ceiling in the center of the box stall in a mounted and retractable cord reel with auto rewind to facilitate unabated movement and natural behavior. The EHB had a surface area of $29,733 \mathrm{~cm}^{2}$ that covered approximately $50 \%$ of the cow (assuming that a $650-$ to $700-\mathrm{kg}$ cow has a surface area of about 55,000 to $59,000 \mathrm{~cm}^{2}$; Elting, 1926; Berman, 2003). Ambient temperature and relative humidity were monitored and recorded every 10 min by a data logger (EL-USB-2 LCR, Lascar Electronics, Erie, PA) and condensed into a daily average. Cows were housed in thermoneutral ambient conditions throughout the experimental period $\left(21.0 \pm 0.6^{\circ} \mathrm{C}, 43.3\right.$ $\pm 1.4 \%$ relative humidity; 66 temperature-humidity index). All procedures were approved by the Iowa State University Institutional Animal Care and Use Committee.

Cows were individually fed a TMR consisting primarily of corn silage ( $34 \%$ of diet DM) once daily (0800 h), and orts were measured daily before feeding. The TMR was formulated to meet or exceed the predicted requirements (NRC, 2001) of energy, protein, minerals, and vitamins. Cows were milked twice daily (0600 and 1800 h), and yield was recorded. Milk samples from each cow were collected on d 2 and 3 of P1 and on d 3 and 7 of P2. Samples were stored at $4^{\circ} \mathrm{C}$ with a preservative (bronopol tablet; D\&F Control Systems, San Ramon, 
CA) until analysis by Dairy Lab Services (Dubuque, IA) using AOAC-approved infrared analysis equipment and procedures (AOAC International, 1995).

During both $\mathrm{P} 1$ and $\mathrm{P} 2$, rectal temperature $(\mathbf{T r})$, skin temperature $(\mathbf{T s})$, respiration rate $(\mathbf{R R})$, and heart rate were obtained twice daily (0600 and $1800 \mathrm{~h}$ ). During the first $48 \mathrm{~h}$ of P2, body temperature indices were obtained hourly to monitor cow health and ensure animal safety (data not shown). Rectal temperatures were measured using a standard digital thermometer (M700 digital thermometer, GLA Agricultural Electronics, San Luis Obispo, CA). Skin temperatures were measured on the neck (not covered by the EHB) using an infrared thermometer (IRT207 Heat Seeker 8:1 mid-range infrared thermometer, General Tools and Instruments, New York, NY). Respiration rates were determined by counting flank movements during a 15-s interval and multiplied by 4 to obtain breaths per minute. Heart rate was determined using a stethoscope placed over the left side of the rib cage behind the elbow, and heart beats were counted for a 15-s interval. This measurement was multiplied by 4 to obtain beats per minute.

Effects of day and period were assessed separately using the MIXED procedure of SAS (version 9.4; SAS Institute Inc., Cary, NC). Dry matter intake, milk yield, body temperature indices, and milk composition during P2 were analyzed using repeated measures with an autoregressive covariance structure and day as the repeated effect. In addition, the effects of period were analyzed separately using the MIXED procedure of SAS with a diagonal covariance structure. Results are reported as least squares means and were considered different when $P \leq 0.05$ and a tendency if $0.05<P<$ 0.10 .

The EHB caused an immediate increase in body temperature indices ( $\mathrm{Tr}$ and $\mathrm{RR}$ ), and the magnitude of increase was characteristic of cows experiencing seasonal HS (Kadzere et al., 2002). Overall and relative to $\mathrm{P} 1$, there was an increase in $\mathrm{Tr}$ and RR at both 0600 and $1800 \mathrm{~h}$ during $\mathrm{P} 2\left(0600 \mathrm{~h} ; 1.0^{\circ} \mathrm{C}\right.$ and 25 breaths/ min, respectively; $1800 \mathrm{~h} ; 1.2^{\circ} \mathrm{C}$ and 29 breaths/min, respectively; $P<0.01$; Figure 2). Heart rate measured at $0600 \mathrm{~h}$ tended to increase with time during P2 $(P$ $=0.06$; Table 1) but was unaffected at the $1800 \mathrm{~h}$ measurement $(P=0.12$; Table 1$)$. No differences were observed in Ts at both 0600 and $1800 \mathrm{~h}$ during P2 relative to $\mathrm{P} 1(P=0.63$ and 0.44 , respectively; Table 1$)$.

Overall, DMI decreased during P2 compared with P1 $(P<0.01)$. By d 5 to 7 of $\mathrm{P} 2, \mathrm{DMI}$ was decreased $25 \%$ relative to $\mathrm{P} 1(P=0.02$; Figure $3 \mathrm{~A})$. Likewise, milk production was decreased overall during P2 compared with P1 $(13 \% ; P<0.01)$, and the nadir $(21 \%)$ occurred on $\mathrm{d} 7$ of $\mathrm{P} 2(P=0.05$; Figure $3 \mathrm{~B})$. Period 2 milk protein tended to decrease $(4.4 \% ; P=0.07)$ compared with P1. In contrast, MUN increased during P2 (33\%; $P<0.01)$ relative to baseline. No other differences were observed in milk content of fat, lactose, TS, and milk SCC during P2 $(P>0.10$; Table 2$)$.

In the present study, both $\mathrm{Tr}$ and $\mathrm{RR}$ were markedly increased by the EHB, indicating that we successfully implemented a stressful heat load. The magnitude of the average change in both $\operatorname{Tr}$ and $\mathrm{RR}\left(\sim 1.1^{\circ} \mathrm{C}\right.$ and 27 breaths/min) was similar to that achieved in climatecontrolled experiments (Rhoads et al., 2009; Shwartz et al., 2009; Wheelock et al., 2010; Baumgard et al., 2011; Cowley et al., 2015). Although the extent of increased body temperature indices was expected, little or no signs of acclimation occurred with time. In other words, we expected $\mathrm{Tr}$ and $\mathrm{RR}$ to peak between $\mathrm{d} 1$ and 2 and then gradually decrease; such changes indicative of acclimation have been observed in natural HS (Kadzere et al., 2002) and in HS studies conducted in environmental chambers (Rhoads et al., 2009; Wheelock et al., 2010). Reasons for the apparent lack of thermal acclimation are not clear, but the blanket obviously obstructed normal routes of heat dissipation (i.e., evaporative cooling via sweating) that are presumably key aspects of acclimation.

Interestingly, Ts was unaffected by the EHB, and this contradicts climate-controlled studies that report increased Ts (Rhoads et al., 2009; Shwartz et al., 2009). Interpreting Ts is difficult because it is a combination of the amount of radiant heat dissipated, ambient

Table 1. Effects of electric heat blanket-induced heat stress on physiological indicators in lactating Holstein cows

\begin{tabular}{|c|c|c|c|c|c|c|c|c|c|c|}
\hline Parameter & $\mathrm{P} 1^{1}$ & \multicolumn{7}{|c|}{ Day } & SEM & $P$-value \\
\hline $0600 \mathrm{~h}$ & 74 & - & 82 & 88 & 77 & 85 & 83 & 81 & 3 & 0.06 \\
\hline $1800 \mathrm{~h}$ & 75 & 91 & 88 & 80 & 83 & 87 & 85 & 86 & 4 & 0.12 \\
\hline \multicolumn{11}{|c|}{ Skin temperature $\left({ }^{\circ} \mathrm{C}\right)$} \\
\hline $0600 \mathrm{~h}$ & 33.7 & - & 35.5 & 34.5 & 34.3 & 35.0 & 34.0 & 33.8 & 0.8 & 0.63 \\
\hline
\end{tabular}

${ }^{1}$ Average of $\mathrm{d} 1$ to 3 of period 1. 
air temperature, wind speed, and water evaporation (Kadzere et al., 2002). During natural HS and in climate-controlled experiments, the temperature gradient between the skin and air is low or actually negative. This is not the case for the EHB model, as the blanket covers only the back and abdominal region (Figure 1; about $50 \%$ of the cow's surface area) and does not fully cover the neck (where Ts was measured). The ambient temperature during the experiment was $21^{\circ} \mathrm{C}$, and thus the temperature gradient between skin and air was much greater than it would be in a natural HS setting.

Heat stress induced by the EHB decreased DMI as expected, and this agrees with the literature (see reviews by Kadzere et al., 2002; West, 2003; Baumgard and
Rhoads 2012, 2013). The gradual and progressive pattern of reduced feed intake is similar to that observed in climate-controlled chamber experiments (Rhoads et al., 2009; Wheelock et al., 2010; Baumgard et al., 2011). Reduced DMI is a highly conserved response to HS and presumably serves as a survival strategy to decrease metabolic heat production (Kadzere et al., 2002; West, 2003; Baumgard and Rhoads, 2013). The EHB also decreased milk yield (21\%); this also was expected. Our previous reports indicate that reduced nutrient intake accounts for only $50 \%$ of the decreased milk yield, with the remaining portion due to changes in nutrient partitioning and immunoactivation (Baumgard and Rhoads, 2012, 2013). However, the current experiment did not
(A)

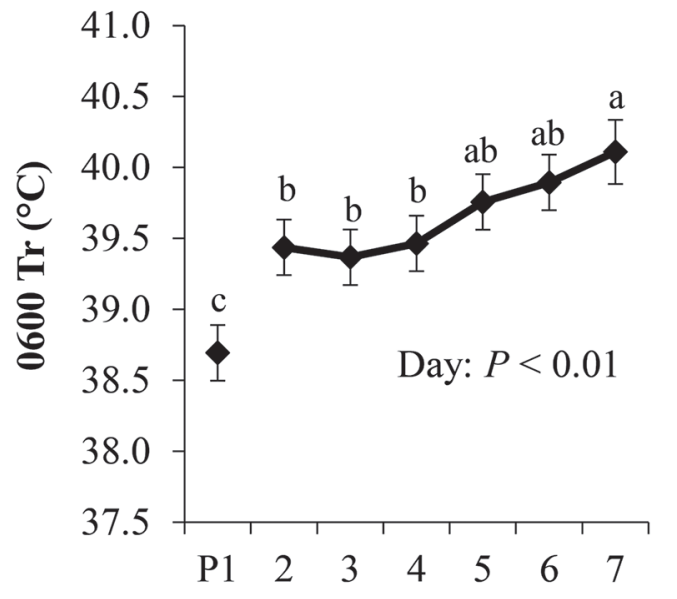

(C)

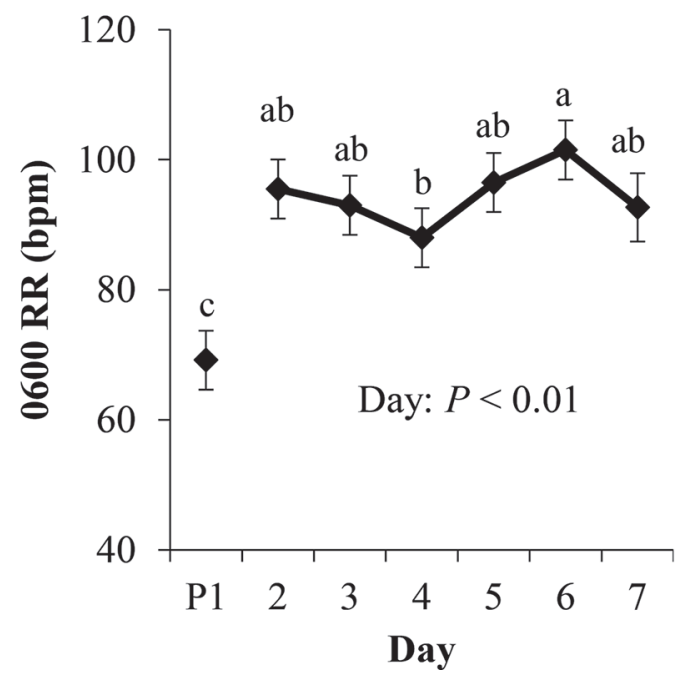

(B)

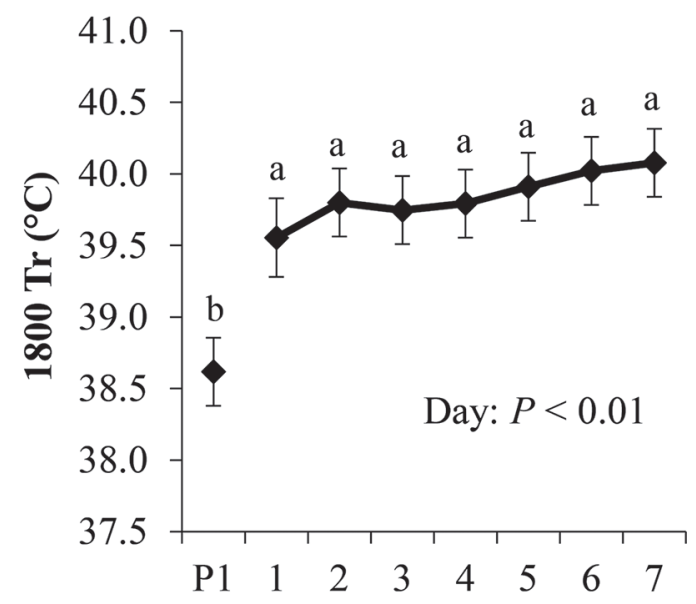

(D)

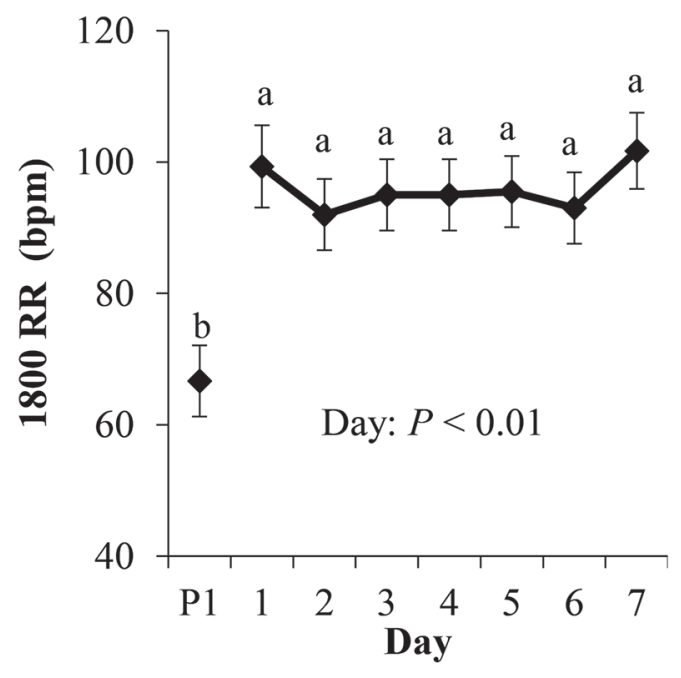

Figure 2. Effects of an electric heat blanket on (A) rectal temperature (Tr) at $0600 \mathrm{~h},(\mathrm{~B}) \mathrm{Tr}$ at $1800 \mathrm{~h},(\mathrm{C})$ respiration rate (RR; bpm $=$ breaths per minute) at $0600 \mathrm{~h}$, and (D) RR at $1800 \mathrm{~h}$ in lactating dairy cows. Values for P1 represent the average of the $3 \mathrm{~d}$ of period 1 . Values with differing letters $(\mathrm{a}-\mathrm{c})$ denote differences $(P<0.05)$ between days. Cows were fitted with an electric heat blanket from d 1 through 7. Results are expressed as LSM \pm SEM. 
(A)

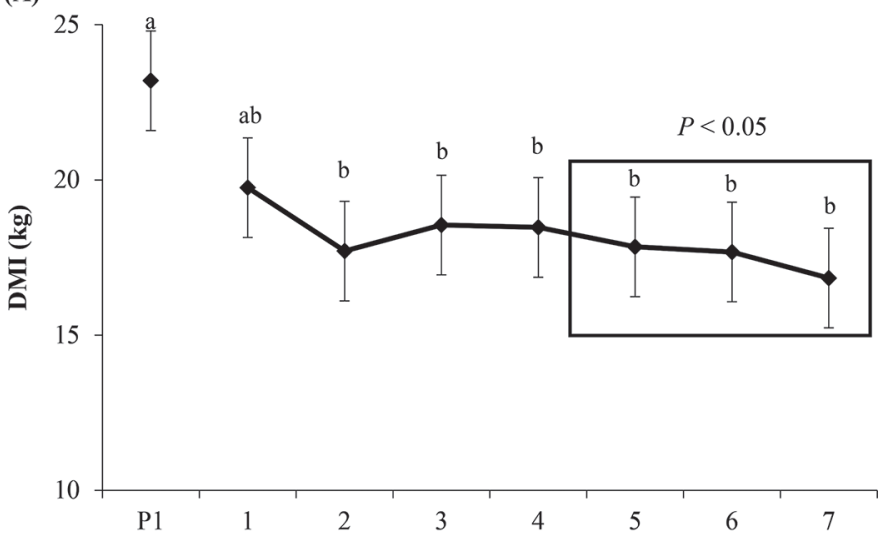

(B)

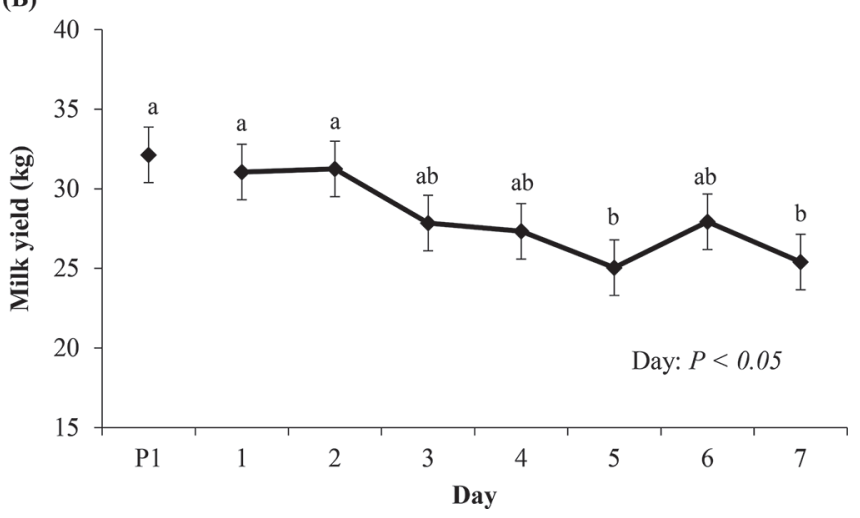

Figure 3. Effects of an electric heat blanket on (A) DMI and (B) milk yield in lactating dairy cows. Values for P1 represent the average of the $3 \mathrm{~d}$ of period 1 (pre-electric heat blanket). Values with differing letters $(\mathrm{a}, \mathrm{b})$ denote differences $(P<0.05)$ between days. Cows were fitted with an electric heat blanket from d 1 through 7 . Results are expressed as LSM \pm SEM.

use a pair-feeding design, and thus we are unable to confirm whether a similar feed intake:milk production relationship exists with the EHB.

Milk protein content tended to decrease during HS, and this agrees with the seasonal pattern of low-summer milk protein (Bouraoui et al., 2002) and climatecontrolled experiments (Rhoads et al., 2009; Shwartz et al., 2009; Wheelock et al., 2010; Baumgard et al., 2011; Cowley et al., 2015). Exact reasons for why HS de-

Table 2. Effect of an electric heat blanket-induced heat stress on milk variables in lactating Holstein cows

\begin{tabular}{lcccr}
\hline Milk parameter & Period 1 & Period 2 & SEM & $P$-value \\
\hline Fat (\%) & 3.91 & 4.04 & 0.20 & 0.66 \\
Protein (\%) & 3.03 & 2.90 & 0.05 & 0.07 \\
Lactose (\%) & 4.81 & 4.80 & 0.02 & 0.89 \\
TS (\%) & 12.7 & 12.6 & 0.2 & 0.95 \\
SCC ( $\times 1,000$ cells) & 91 & 106 & 24 & 0.66 \\
MUN (mg/dL) & 12.8 & 17.0 & 0.6 & $<0.01$ \\
\hline
\end{tabular}

creases milk protein content are not clear, but increased extramammary AA utilization (Gao et al., 2017) and a downregulation of mammary protein synthesizing machinery (Bernabucci et al., 2010; Cowley et al., 2015) are 2 probable explanations. The EHB increased MUN; this agrees with previous climate-controlled studies (Wheelock et al., 2010; Cowley et al., 2015) and is likely the result of skeletal muscle mobilization to support gluconeogenesis and acute phase protein synthesis (Baumgard and Rhoads, 2013). As opposed to the characteristic decrease in milk fat typically observed during the summer (Hays, 1926; Bouraoui et al., 2002), we did not detect EHB-induced decreased milk fat content. However, the lack of an HS effect on milk fat agrees with most climate-controlled HS reports (Rhoads et al., 2009; Shwartz et al., 2009; Cowley et al., 2015) and suggests that low summer milk fat is not directly caused by HS.

In conclusion, employing the EHB increased body temperature indices ( $\mathrm{Tr}$ and $\mathrm{RR}$ ) and negatively affected production parameters. Thus, utilizing the EHB is a relatively low-cost and scientifically valuable, albeit unconventional, research technique to model and simulate HS in lactating dairy cows. Importantly, the EHB is likely not a good technique for studying products whose mode of action is to facilitate heat dissipation via radiation, convection, or evaporation (vasodilatation at the periphery or sweating), as the blanket markedly interferes with normal routes of heat loss. However, if experimental objectives are to study the biological consequences of HS or to test products with activity within the gastrointestinal tract or via modifying metabolism, then the EHB is a feasible research strategy.

\section{REFERENCES}

AOAC International. 1995. AOAC official method 972.16. Fat, lactose, protein, and solids in milk. Mid infrared spectroscopic method. Pages 23-26 in Official Methods of Analysis. 16th ed. Vol. 2. AOAC International, Arlington, VA.

Baumgard, L. H., and R. P. Rhoads. 2012. Ruminant production and metabolic responses to heat stress. J. Anim. Sci. 90:1855-1865.

Baumgard, L. H., and R. P. Rhoads. 2013. Effects of heat stress on postabsorptive metabolism and energetics. Annu. Rev. Anim. Biosci. 1:311-337.

Baumgard, L. H., J. B. Wheelock, S. R. Sanders, C. E. Moore, H. B. Green, M. R. Waldron, and R. P. Rhoads. 2011. Postabsorptive adaptations to heat stress and monensin supplementation in lactating Holstein cows. J. Dairy Sci. 94:5620-5633.

Berman, A. 2003. Effects of body surface area estimates on predicted energy requirements and heat stress. J. Dairy Sci. 86:3605-3610.

Bernabucci, U., N. Lacetera, L. H. Baumgard, R. P. Rhoads, and A. Nardone. 2010. Metabolic and hormonal acclimation to heat stress in domesticated ruminants. Animal 4:1167-1183.

Bouraoui, R., M. Lahmar, A. Majdoub, M. Djemli, and R. Belyea. 2002. The relationship of temperature-humidity index with milk production of dairy cows in a Mediterranean climate. Anim. Res. 51:479-491.

Cowley, F. C., D. G. Barber, A. V. Houlihan, and D. P. Poppi. 2015. Immediate and residual effects of heat stress and restricted intake 
on milk protein and casein composition and energy metabolism. J. Dairy Sci. 98:2356-2368.

Das, R., L. Sailo, N. Verma, P. Bharti, J. Saikia, Imtiwati, and R. Kumar. 2016. Impact of heat stress on health and performance of dairy animals: A review. Vet. World 9:260-268.

Elting, E. C. 1926. A formula for estimating surface area of dairy cattle. J. Agric. Res. Washington 33:269-279.

Gao, S. T., J. Guo, S. Y. Quan, X. M. Nan, M. V. Sanz Fernandez, L. H. Baumgard, and D. Bu. 2017. The effects of heat stress on protein metabolism in lactating Holstein cows. J. Dairy Sci. 100:5040-5049.

Hays, W. P. 1926. The effect of environmental temperature on the percentage of fat in cow's milk. J. Dairy Sci. 9:219-235.

Kadzere, C. T., M. R. Murphy, N. Silanikove, and E. Maltz. 2002. Heat stress in lactating dairy cows: A review. Livest. Prod. Sci. 77:59-91.

Key, N., and S. Sneeringer. 2014. Potential effects of climate change on the productivity of U.S dairies. Am. J. Agric. Econ. 96:1136-1156.

Liu, J., G. Ye, Y. Zhou, Y. Liu, L. Zhao, X. Chen, D. Huang, S. F. Liao, and K. Huang. 2014. Feeding glycerol-enriched yeast culture improves performance, energy status, and heat shock protein gene expression of lactating Holstein cows under heat stress. J. Anim. Sci. 92:2494-2502.
Nardone, A., B. Ronchi, N. Lacetera, M. S. Ranieri, and U. Bernabucci. 2010. Effects of climate changes on animal production and sustainability of livestock systems. Livest. Sci. 130:57-69.

National Research Council. 2001. Nutrient Requirements of Dairy Cattle. 7th rev. ed. Nat. Acad. Press, Washington, DC.

Rhoads, M. L., R. P. Rhoads, M. J. VanBaale, R. J. Collier, S. R. Sanders, W. J. Weber, B. A. Crooker, and L. H. Baumgard. 2009. Effects of heat stress and plane of nutrition on lactating Holstein cows: I. Production, metabolism, and aspects of circulating somatotropin. J. Dairy Sci. 92:1986-1997.

Shwartz, G., M. L. Rhoads, M. J. VanBaale, R. P. Rhoads, and L. H. Baumgard. 2009. Effects of a supplemental yeast culture on heatstressed lactating Holstein cows. J. Dairy Sci. 92:935-942.

Spiers, D. E., J. N. Spain, J. D. Sampson, and R. P. Rhoads. 2004. Use of physiological parameters to predict milk yield and feed intake in heat-stressed dairy cows. J. Therm. Biol. 29:759-764.

West, J. W. 2003. Effects of heat stress on production in dairy cattle. J. Dairy Sci. 86:2131-2144.

Wheelock, J. B., R. P. Rhoads, M. J. VanBaale, S. R. Sanders, and L. H. Baumgard. 2010. Effects of heat stress on energetic metabolism in lactating Holstein cows. J. Dairy Sci. 93:644-655. 